\title{
The Impacts of Prepared Plasma-Activated Medium (PAM) Combined with Doxorubicin on the Viability of MCF-7 Breast Cancer Cells: A New Cancer Treatment Strategy
}

\author{
Setareh Zahedian ${ }^{1}$, Azadeh Hekmat*1, \\ Saeed Hesami Tackallou ${ }^{2}$, Mahmood Ghoranneviss ${ }^{3}$
}

\begin{abstract}
Background: For many years, the chemotherapeutic agent doxorubicin (DOX) has been used to treat various cancers; however, DOX initiates several critical adverse effects. Many studies have reported that non-thermal atmospheric pressure plasma can provide novel, but challenging, treatment strategies for cancer patients. To date, tissues and cells have been treated with plasma-activated medium (PAM) as a practical therapy. Consequently, due to the harmful adverse effects of DOX, we were motivated to elucidate the impact of PAM in the presence of DOX on MCF-7 cell proliferation.

Methods: MTT assay, N-acetyl-L-cysteine (NAC) assay, and flow cytometry analysis were utilized in this research.

Results: The results demonstrated that $0.45 \mu \mathrm{M}$ DOX combined with 3-min PAM significantly induced apoptosis $(\mathrm{p}<0.01)$ through intracellular ROS generation in MCF-7 when compared with $0.45 \mu \mathrm{M}$ DOX alone or 3-min PAM alone. In contrast, after treatment with $0.45 \mu \mathrm{M}$ DOX plus 4-min PAM, cell necrosis was increased. Hence, DOX combined with 4-min PAM has cytotoxic effects with different mechanisms than 4-min PAM alone, in which the number of apoptotic cells increases.

Conclusions: Although further investigations are crucial, low doses of DOX plus 3-min PAM could be a promising strategy for cancer therapy. The findings from this research may offer advantageous and innovative clinical strategies for cancer therapy using PAM.
\end{abstract}

Keywords: Apoptosis, Breast cancer lymphedema, Doxorubicin, Plasma-activated medium (PAM), Necrosis.

\section{Introduction}

Breast cancer is the most widespread malignancy among females worldwide, accounting for the greatest percentage of deaths $(15.5 \%)$ from all cancers in women. It was estimated the number of new cases in 2020 would exceed 2.2 million $(1,2)$. Subsequently, it seems obvious that more effective treatments than those currently in use are sorely needed. Current cancer treatments include hormone therapy, chemotherapy, radiotherapy, immunotherapy, and surgery. Some of these treatments have serious deleterious side effects in patients (3-5).

Anthracycline drugs are one of the most important drug classes in chemotherapy. Doxorubicin (DOX), an anthracycline component derived from Streptomyces peucetius, has been used to treat various cancers including those of breast, head and neck, lung, liver, and ovaries. Numerous mechanisms have 
been proposed to describe DOX antitumor activity; these include disruption of topoisomerase II $\alpha$ function, protein and nucleic acid synthesis inhibition, DNA intercalation or alkylation, reactive oxygen species (ROS) production, and interaction with the cell membrane $(6,7)$. However, DOX initiates several critical adverse effects including congestive heart failure (CHF), myelosuppression, and nausea $(5,8)$. Additionally, multidrug resistance (MDR) of malignant cells to DOX remains the most significant barrier to effective treatment.

In 1928, plasma was introduced as a fourth phase of matter (9). This ionized gas is comprised of photons, electrons, ions, and neutrals, which include molecules, excited atoms, and radicals (10-12). Cold atmospheric plasma (CAP) is a plasma in which the temperature of the heavy particles is between 25 and $45^{\circ} \mathrm{C}$ (13). Applications of plasma for acne, aesthetics, dental caries, and endoscopic applications are well known (10, 14-16). Recently, indirect and direct CAP treatment became a new subject in plasma medicine. According to the literature, non-thermal atmospheric plasma (NTAP) can be utilized for cancer treatment with few side effects $(9$, 17-20). In indirect CAP therapy, the CAPstimulated solutions (PSS) are applied to affect malignant cell growth in vivo or in vitro by injecting PSS into the malignant tissue. One of the advantages of PSS treatment is that it can be stored for a long time at $-80{ }^{\circ} \mathrm{C}$ (by optimizing the composition of the solution), so, it can be utilized without dependence on the CAP-producing device (21). Current studies reported that plasma can affect malignant cells indirectly with water irradiated by plasma or previously prepared medium, termed plasmaactivated water (PAW) and plasma-activated medium (PAM), respectively (22). The antitumor properties of PAM are due to its ability to eliminate cell survival elements and generate cell death factors such as singlet oxygen, nitric oxide (NO), superoxide, and the hydroxyl radical. These relatively short-lived death factors can be switched to other relatively long-lived species; for example, nitrate/nitrite (NOx) and hydrogen peroxide $\left(\mathrm{H}_{2} \mathrm{O}_{2}\right)(18,23)$. Thus, PAM treatments may represent valuable and innovative tools for malignant therapy (12).

Due to resistance to DOX and its harmful adverse effects, the scientific community is obliged to design novel cancer treatments. Therefore, we aimed to determine the effect of DOX in the presence of PAM prepared at various time points on $\mathrm{MCF}-7$ cell proliferation by MTT and N-acetyl-L-cysteine (NAC) assays, and flow cytometry. The results of this research could offer advantageous and innovative clinical strategies for cancer therapy in the future.

\section{Materials and Methods Materials}

The MCF-7 human breast adenocarcinoma cell line was purchased from the Iranian Biological Resource Center (IBRC C10082), Iran. 3-(4,5 dimethylthiazol-2-yl)-2,5diphenyltetrazolium bromide (MTT) was acquired from Sigma Aldrich Co., USA. Doxorubicin hydrochloride (a bright red crystalline powder with the empirical formula $\mathrm{C}_{27} \mathrm{H}_{29} \mathrm{NO}_{11}$ under the trade name Adriamycin) was purchased from Hetero Labs Limited Co, India. The fetal bovine serum (FBS) and trypsin-EDTA were obtained from Gibco, USA. Dimethylsulfoxide (DMSO) and N-acetyl-Lcysteine (NAC) were obtained from Merck, Germany. Modified Eagle Medium without sodium pyruvate (DMEM/F12), streptomycin, and penicillin were obtained from Bio-idea, Iran. The Annexin FITC kit was obtained from IQ product, Netherlands.

\section{Cells and Cell Culture}

MCF-7 cells were cultured in DMEM/F12 medium supplemented with FBS $(10 \%$, heatinactivated) and $1 \%$ Pen Strep (10000 units/mL penicillin and $10 \mathrm{mg} / \mathrm{mL}$ streptomycin in a humidified incubator containing $5 \% \mathrm{CO}_{2}$ at $37{ }^{\circ} \mathrm{C}$. Upon reaching greater than $80 \%$ confluence, cells were subcultured. 
Preparation of plasma-activated medium (PAM) In this study, the plasma jet comprised a pyrex nozzle tube as an insulating shield $(\mathrm{OD}=4 \mathrm{~mm}$ and $\mathrm{ID}=2 \mathrm{~mm}$ ), and the working gas was fed from the tube tip as previously described (24). The device produced a plasma jet with argon gas $(99.99 \%)$ ) flow (flow rate was maintained constant at 2 standard L/min (slm)) by utilizing a voltage of $10 \mathrm{kV}$ at room atmosphere. A $6 \mathrm{~mm}$ copper electrode covered the tube and was linked to the power supply. In brief, PAM was produced by exposing plasma to $3 \mathrm{~mL}$ of DMEM without FBS and antibiotics in 6-well plates with $35 \mathrm{~mm}$ well diameters. The distance between the media surface and the plasma source was $6 \mathrm{~mm}$. The PAM irradiation times were 1, 2, 3, and 4 min. After that Pen Strep and FBS were added, and the PAM was added to cells immediately.

\section{Samples preparation}

Log-phase MCF-7 cells were treated with trypsin-EDTA and seeded in 96-well plates. The cells were washed with PBS buffer, $1 \times 10^{5}$ cells/well were seeded into 96-well plates, and $180 \mu \mathrm{l}$ of growth medium were added to each well. The cells were randomly divided into one control and four experimental groups. The experimental groups were (1) cells incubated with $80 \mu \mathrm{l}$ of PAM (plasma irradiated for 1,2 , 3 , or $4 \mathrm{~min}$ ) for $48 \mathrm{~h},(2)$ cells incubated with sterilized DOX at $0.025,0.1,0.2,0.4,0.62$, and $1 \mu \mathrm{M}$ for $48 \mathrm{~h}$, (3) cells incubated with 3-min PAM plus sterilized DOX $(0.45 \mu \mathrm{M})$ for $48 \mathrm{~h}$, and (4) cells incubated with 4-min PAM plus sterilized DOX $(0.45 \mu \mathrm{M})$ for $48 \mathrm{~h}$. Control cells received no PAM or DOX. In this study, the variations in temperature and $\mathrm{pH}$ of the medium before and after plasma irradiation were negligible.

\section{Cell viability measurements}

After $48 \mathrm{~h}$ of incubation $0.5 \mathrm{mg} / \mathrm{ml} \mathrm{MTT}(20 \mu \mathrm{l})$ was added to the control and experimental cells and the cells were incubated for $3 \mathrm{~h}$ in a $\mathrm{CO}_{2}$ incubator at $37{ }^{\circ} \mathrm{C}$. Later, the insoluble formazan formed was dissolved in $100 \mu \mathrm{l}$ of DMSO and mixed $(25,26)$. The optical density (OD) of each well was measured at $570 \mathrm{~nm}$ against a reagent blank on an ELISA reader (ELx808, BioTek Instruments, Inc., USA). Each trial was repeated 4 times.

\section{Morphology alterations research}

After $48 \mathrm{~h}$ of incubation, the medium was removed from the wells and the cells were washed once with $2 \mathrm{ml}$ of cold PBS buffer ( 0.01 $\mathrm{M}, \mathrm{pH}$ 7.4). The cells were photographed on an inverted microscope (INV100; BEL Engineering, Italy), and morphological alterations were determined as previously described (27).

\section{Measurement of reactive oxygen species (ROS)} The effect of DOX plus PAM on ROS generation in the absence or presence of NAC was investigated. NAC powder was dissolved in DMEM, then the cells were incubated with 0-, 3, 4-, or 5-mM NAC for $3 \mathrm{~h}$ in a $\mathrm{CO}_{2}$ incubator at $37^{\circ} \mathrm{C}$. The cells were then incubated with DOX and/or PAM. After $48 \mathrm{~h}, 20 \mu \mathrm{l}$ of $0.5 \mathrm{mg} / \mathrm{ml}$ of MTT were added to each well and cell viability was determined by MTT assay.

\section{Flow cytometry}

Annexin $\mathrm{V}$ binding was determined via the Annexin FITC kit. Cells were seeded into 6-well plates at $10^{6}$ cells/well for $48 \mathrm{~h}$, then treated with PAM and/or DOX. The cells were collected by centrifugation for $5 \mathrm{~min}$ at $1000 \times \mathrm{g}$ and washed twice with PBS buffer (0.01 M, pH 7.4), suspended in $100 \mu \mathrm{L}$ of Annexin $\mathrm{V}$ binding buffer (10 mM HEPES/NaOH, pH 7.4, 140 mM $\mathrm{NaCl}$, and $2.5 \mathrm{mM} \mathrm{CaCl} 2$ ), and double-stained with $5 \mu \mathrm{L}$ of propidium iodide and $5 \mu \mathrm{L}$ of FITClabeled Annexin V. All samples were incubated for $30 \mathrm{~min}$ in the dark at room temperature and analyzed by flow cytometry on a BD FACSCalibur $^{\mathrm{TM}}$ (BD Biosciences Inc., USA).

\section{Statistical analysis}

Significant differences were evaluated by t-test using GraphPad Prism Software (Version 8.4.3, GraphPad Software Inc., San Diego, USA). GraphPad Prism also was utilized to plot graphs. The flow cytometry data were analyzed using FlowJo software (Version 7.6.1). All data were reported as means \pm standard deviations. 


\section{Results}

\section{Growth rates of MCF-7 cells}

We assessed whether DOX and/or PAM affected cell viability. As described in materials and methods, MCF-7 cells were first examined after incubation with increasing DOX concentrations for $48 \mathrm{~h}$. Cell viability decreased in a dose-dependent manner (Fig. 1a). The $\mathrm{IC}_{50}$ (50\% inhibition concentration) of DOX was determined to be $0.49 \mu \mathrm{M}$. The MTT assay also demonstrated that PAM prepared with increasing irradiation periods reduced cell viability in a time-dependent manner (Fig. 1b). The addition of 1- or 2-min
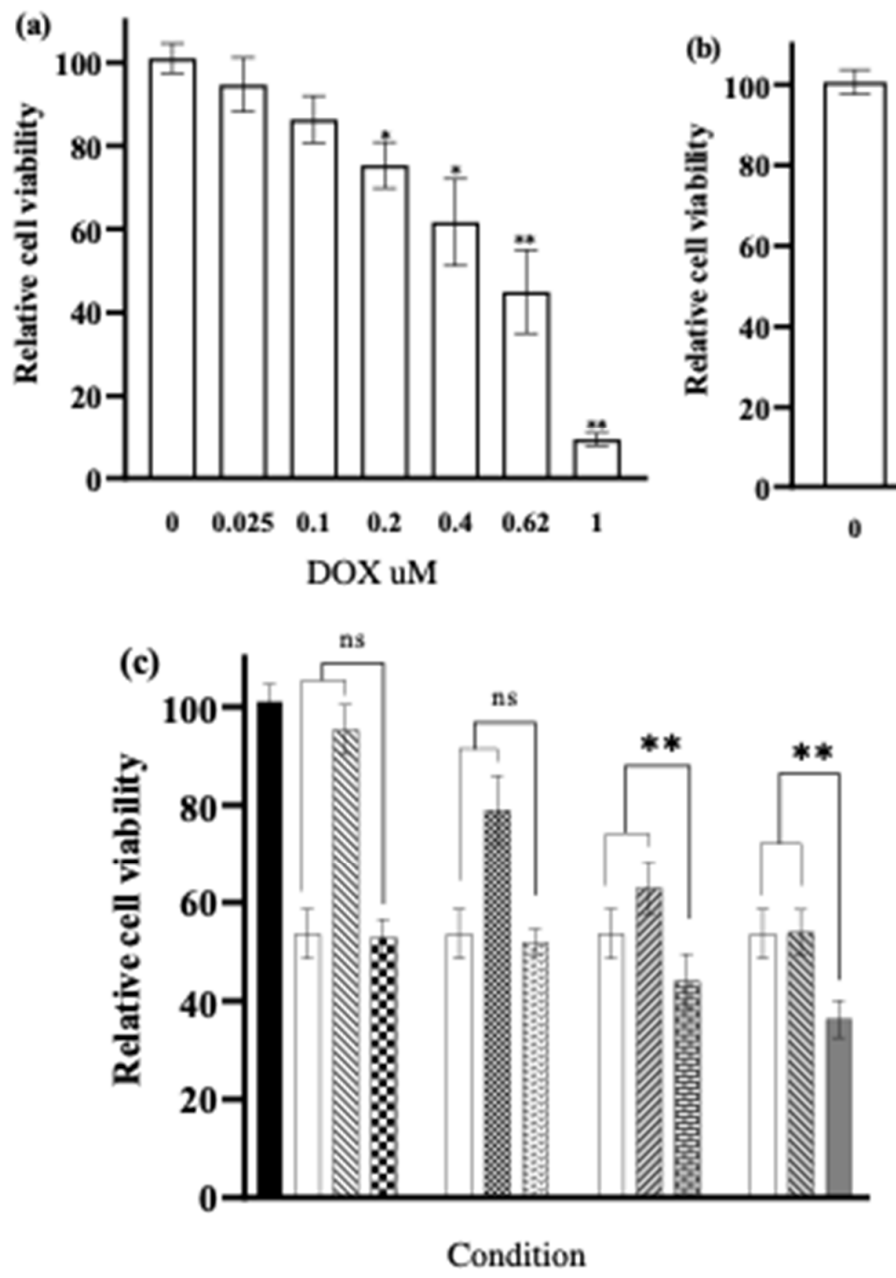

PAM did not affect cell viability. In the followup experiments, cells were incubated in 0.45 $\mu \mathrm{M}$ DOX (less than the $\mathrm{IC}_{50}$ ) plus 3- or 4-min PAM for $48 \mathrm{~h}$ to attain the optimum combination condition that impacted the majority of tumor cells. Cell viability was significantly less in the DOX plus 3-min PAM than in the DOX or 3-min PAM, and in the DOX plus 4-min PAM than in the DOX or 4min PAM (Fig. 1c, $p<0.01$ for both). The addition of 1- or 2-min PAM to DOX did not significantly affect cell viability compared to DOX alone (Fig. 1c).

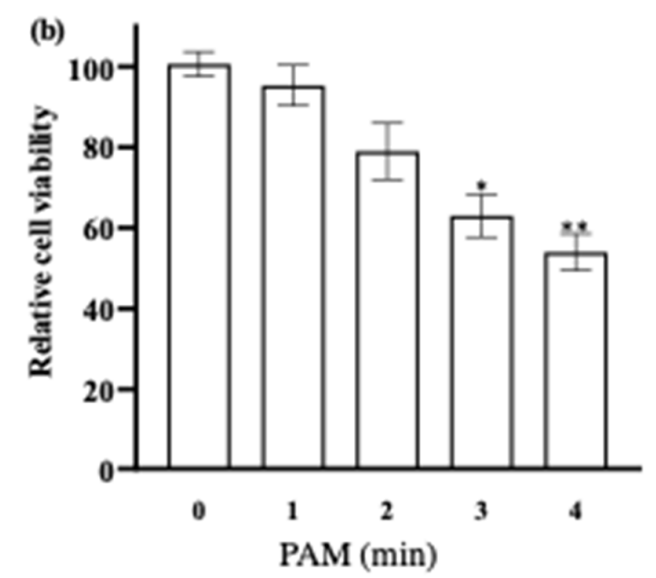

Fig. 1. MTT assay of MCF-7 cells after $48 \mathrm{~h}$ incubations with: (a) varying concentrations of DOX $\left({ }^{*} \mathrm{p}<0.05\right.$ and ${ }^{* *} \mathrm{p}<0.01 \mathrm{vs}$. the untreated control group), (b) PAM synthesized at increasing time durations $\left({ }^{*} \mathrm{P}<0.05\right.$ and ${ }^{* *} \mathrm{P}<0.01$ vs. the untreated control group), (c) MCF-7 cell growth (\%) of $0.45 \mu \mathrm{M}$ DOX with 1-, 2-, 3-, and 4-min PAM ${ }^{* *} \mathrm{P}<0.01$ vs. the PAM-treated and DOX-treated group; $\mathrm{ns}=$ not specified). Values are means \pm standard deviations 


\section{Morphological analysis}

Cell morphology was examined after incubations with 2-, 3-, or 4- min PAM, DOX, and DOX plus PAM for $48 \mathrm{~h}$. The cells grew as monolayers (Fig. 2a). The cells treated with 2-min PAM retained their polygonal shape and normal angularity (Fig 2b); however, cells treated with 3-min PAM (Fig. 2c), 4-min PAM (Fig. 2d), or DOX (Fig. 2e) displayed altered morphologies and some cells rounded. Treatment with DOX plus 3-min PAM (Fig. 2f) or 4-min PAM (Fig. 2g) changed the cell morphology dramatically; cells became rounded and detached from the dishes.
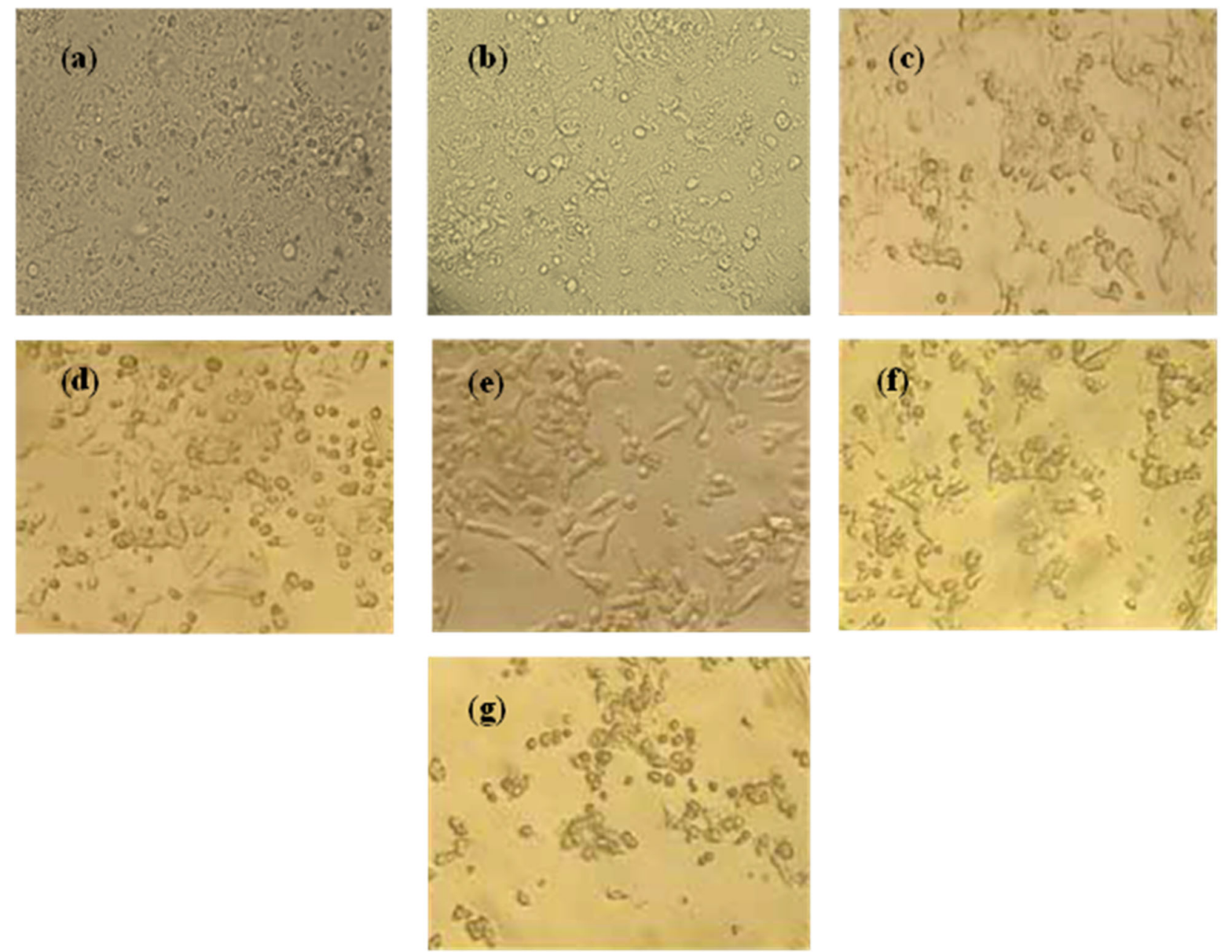

Fig. 2. Morphological analyses of MCF-7 cells: (a) control cells, (b) incubated $48 \mathrm{~h}$ with 2-min PAM, (c) incubated $48 \mathrm{~h}$ with 3-min PAM, (d) incubated $48 \mathrm{~h}$ with 4-min PAM, (e) incubated $48 \mathrm{~h}$ with $0.45 \mu \mathrm{M}$ DOX, (f) incubated $48 \mathrm{~h}$ with0.45 $\mu \mathrm{M}$ DOX plus 3-min PAM, (g) incubated $48 \mathrm{~h}$ with $0.45 \mu \mathrm{M}$ DOX plus 4-min PAM.

\section{ROS measurements}

To explore whether oxidative stress contributed to cytotoxicity, cells were treated with DOX, 3- or 4-min PAM, or DOX plus PAM in the presence of $0-, 3-, 4-$, or 5-mM NAC. Pretreatment with NAC inhibited DOXinduced cytotoxicity at all NAC concentrations in a dose-dependent manner ( $\mathrm{p}<0.05$ (for 3$\mathrm{mM}$ NAC) and $\mathrm{p}<0.01$ (for $4-$ and $5-\mathrm{mM}$ NAC)) (Fig. 3a). The results were slightly different with 3- and 4-min PAM; 3-mM NAC had almost no effect; however, 4- and 5-mM NAC inhibited PAM-induced cytotoxicity in a dose-dependent manner $(\mathrm{p}<0.05$ for $4-\mathrm{mM}$ $\mathrm{NAC}$ and $\mathrm{p}<0.01$ for 5 -mM NAC) (Fig. 3b). In the follow-up experiments, cells were treated with DOX plus 3-min PAM and DOX plus 4-min PAM in the presence of 5-mM NAC. It was observed that 5-mM NAC significantly inhibited DOX plus 3-min PAM and DOX plus 4-min PAM cytotoxicity (Fig. $3 \mathrm{c}, \mathrm{p}<0.01$ for both). 

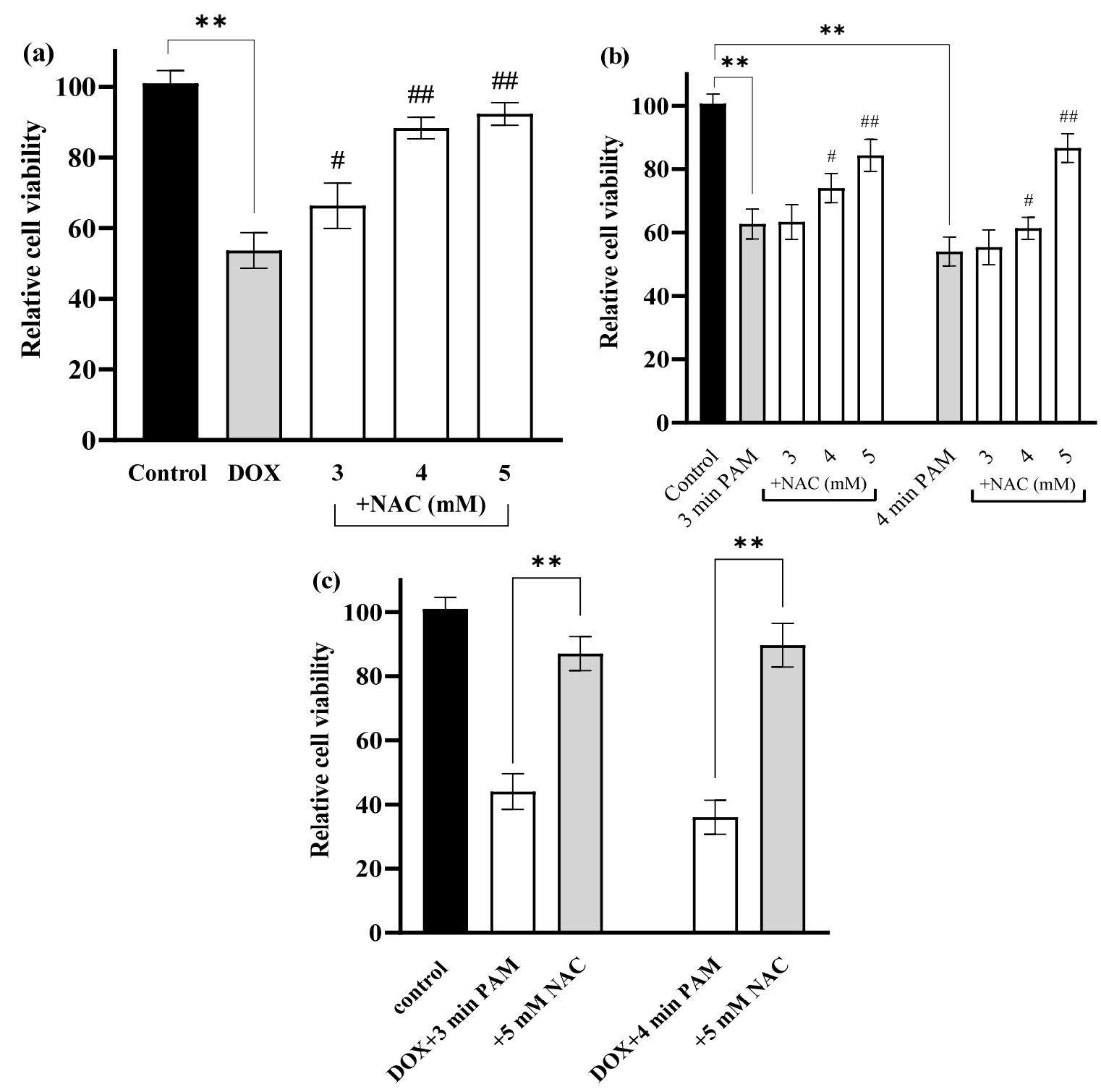

Fig. 3. Measurement of the reactive oxygen species (ROS) generation by MTT assay. MCF-7 cells were incubated for $3 \mathrm{~h}$ at $37{ }^{\circ} \mathrm{C}$ with 0-, 3-, 4-, or 5-mM NAC; then incubated for $48 \mathrm{~h}$ with: (a) $0.45 \mu \mathrm{M}$ DOX (**p $<0.01$ vs. the control group; ${ }^{*} \mathrm{p}<0.05$ and ${ }^{\# \#} \mathrm{p}<$ 0.01 vs. the DOX-treated group) and (b) 3 - or $4-\min$ PAM (**p $<0.01$ vs. the control group; ${ }^{*} p<0.05$ and ${ }^{\# \#} p<0.01$ vs. the PAMtreated group). In (c) two sets of cells were first incubated for $3 \mathrm{~h}$ at $37{ }^{\circ} \mathrm{C}$ with $5 \mathrm{mM} \mathrm{NAC}$; then one set was incubated for $48 \mathrm{~h}$ with $45 \mu \mathrm{M}$ DOX plus 3-min PAM and another set with $45 \mu \mathrm{M}$ DOX plus 4-min PAM. One other set of cells received $45 \mu \mathrm{M}$ DOX plus 3-min PAM and another set received $45 \mu \mathrm{M}$ DOX plus 4-min PAM. These cells received no NAC. Values are means \pm standard deviations; $* *$ indicates $\mathrm{p}<0.01$.

\section{Effects of DOX plus PAM on cell apoptosis and necrosis}

The cells were incubated with $0.45 \mu \mathrm{M}$ DOX, 3- and 4-min PAM, or DOX plus PAM, and analyzed by flow cytometry (Fig. 4). The early apoptotic cell percentages were dramatically greater in the $0.45 \mu \mathrm{M}$ DOX, 4-min PAM, and DOX plus 3-min PAM-treated cells (32.08, $29.09,41.39$, respectively) compared to control cells (7.97). The late apoptotic cells percentages were also greater in the $0.45 \mu \mathrm{M}$ DOX, 4-min PAM, and DOX plus 3-min PAM-treated cells $(15.21,14.70,15.22$, respectively) compared to control cells (2.54). However, the early apoptotic cell percentages did not change in the DOX plus 4-min PAMtreated cells compared to control cells $(7.61 \%$ 
vs 7.97) (Fig. 4g). Surprisingly, the percentage of necrotic cells was dramatically greater in the DOX plus 4- min PAM-treated cells than in
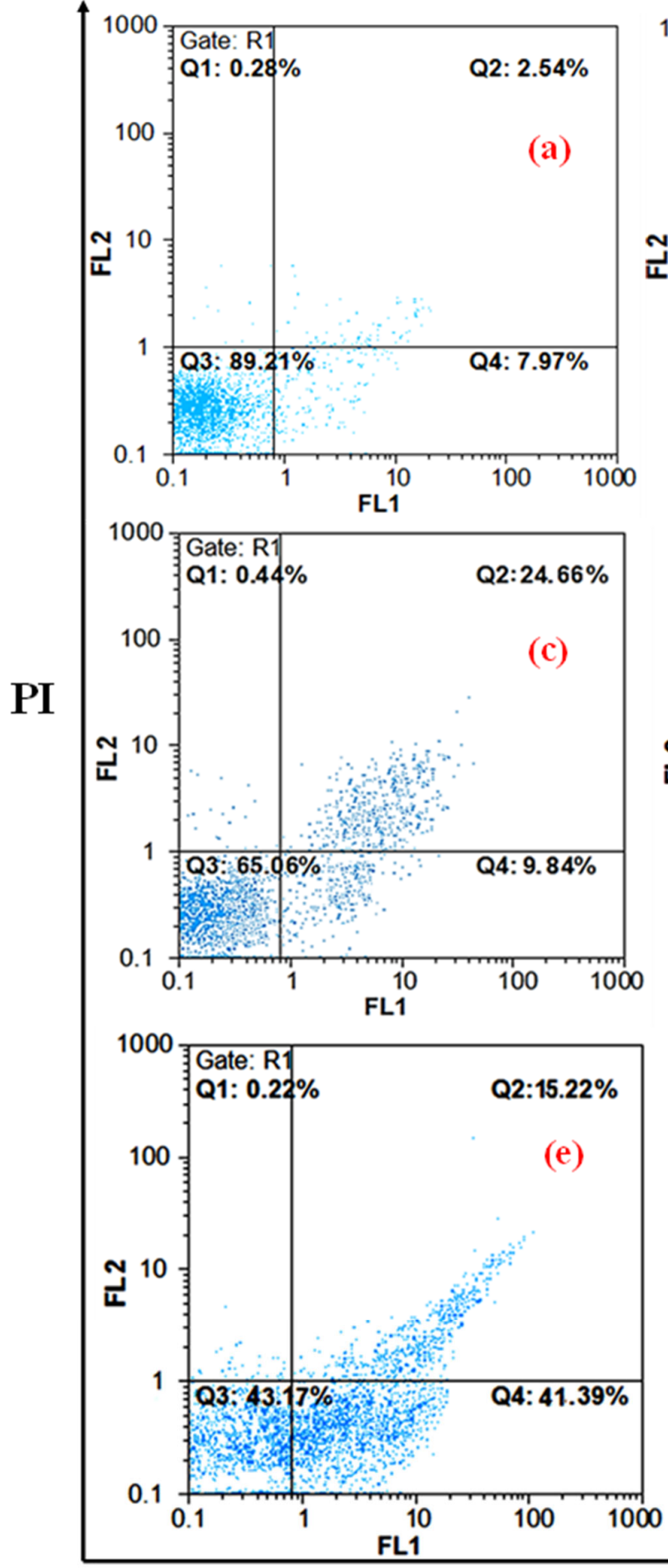

controls ( 44.8 vs $0.28 \%, p<0.01$ ), but necrosis was similar to controls for all other incubated cells (Figs. 4g).
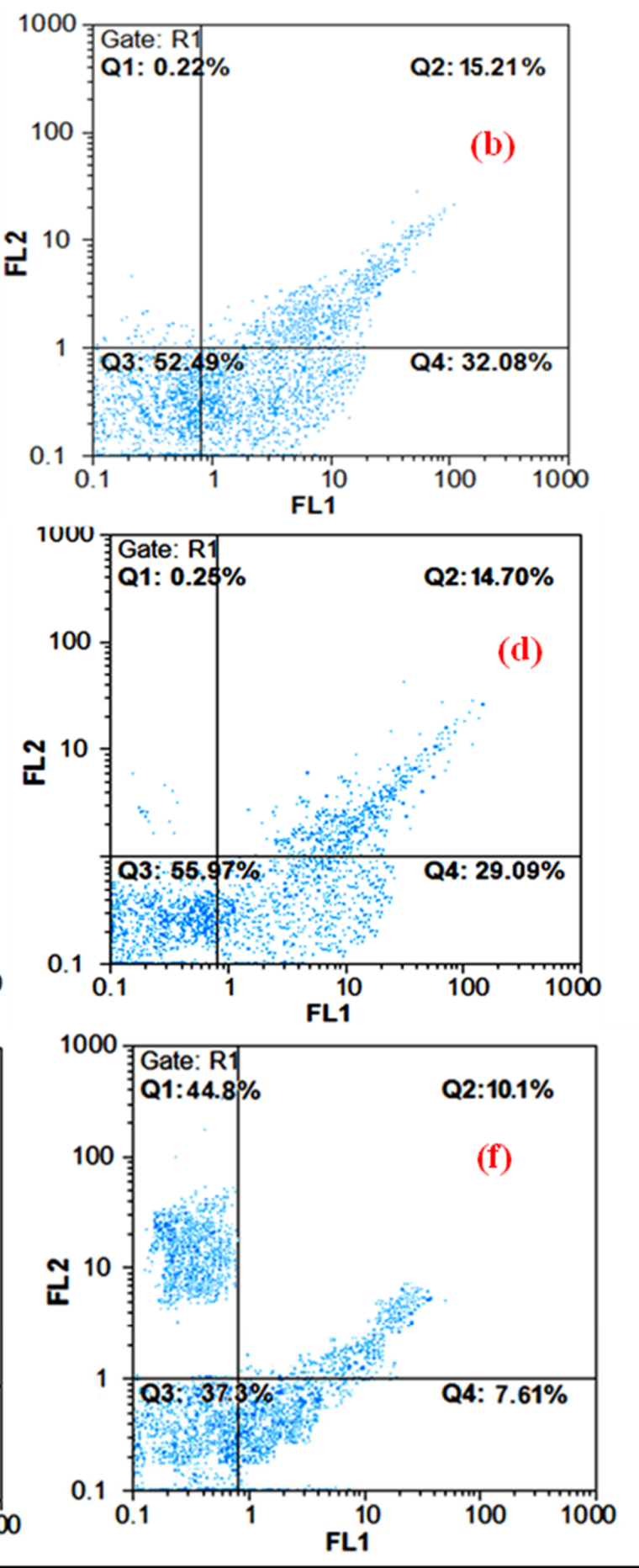

Annexin V 


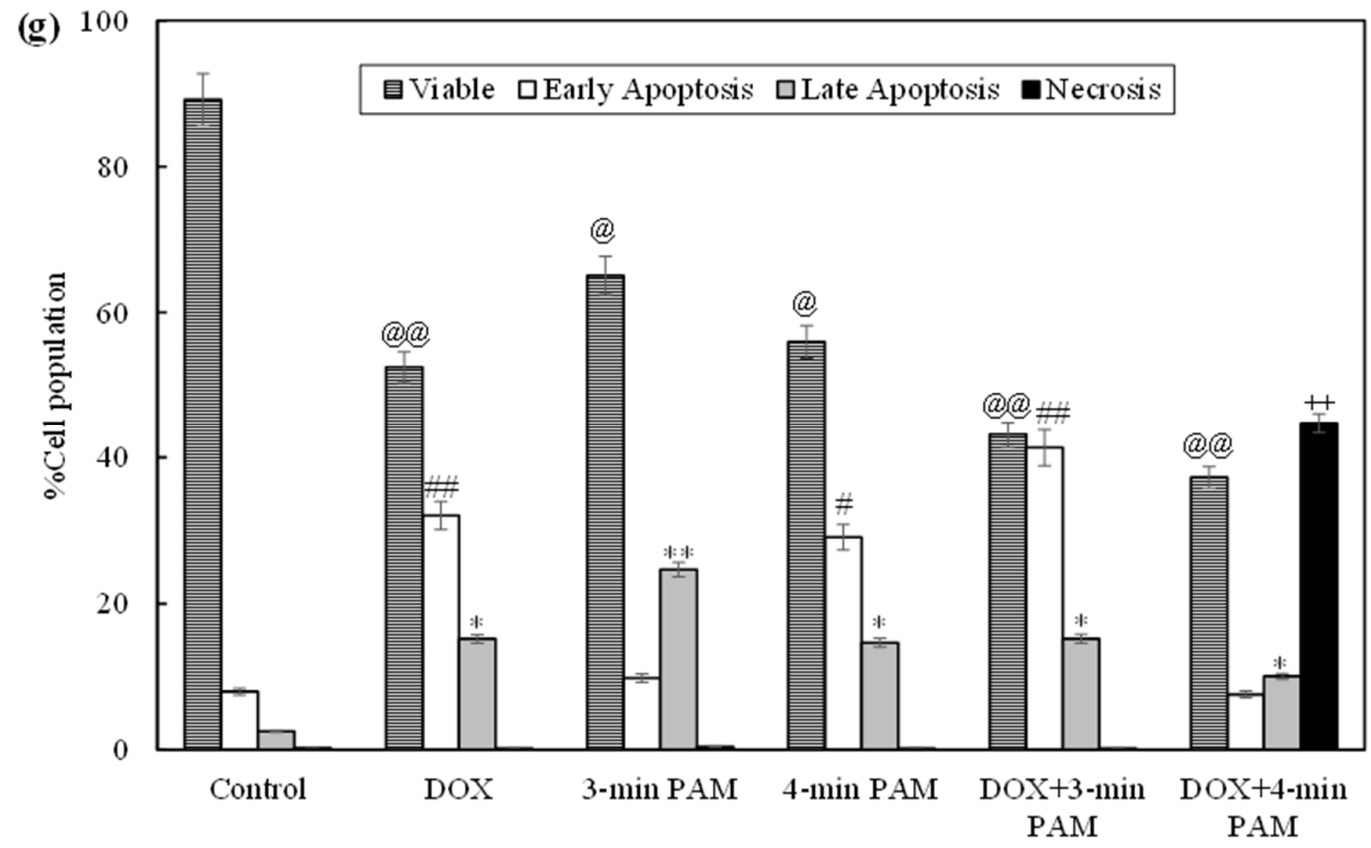

Fig. 4. Flow cytometry analyses of MCF-7 cells: (a) control cells, (b) cells incubated for $48 \mathrm{~h}$ with $0.45 \mu \mathrm{M}$ DOX, (c) cells incubated for $48 \mathrm{~h}$ with 3-min PAM, (d) cells incubated for $48 \mathrm{~h}$ with 4-min PAM, (e) cells incubated for $48 \mathrm{~h}$ with $0.45 \mu \mathrm{M} \mathrm{DOX}$ plus 3-min PAM, (f) cells incubated for $48 \mathrm{~h}$ with $0.45 \mu \mathrm{M}$ DOX plus 4-min PAM. (g) percentage of cell populations by flow cytometry analysis ( $\left({ }^{@} \mathrm{p}<0.05\right.$ and ${ }^{@} @ \mathrm{p}<0.01$ vs. the control group; ${ }^{*} \mathrm{p}<0.05$ and ${ }^{* *} \mathrm{p}<0.01$ vs. the control group; ${ }^{\#} \mathrm{p}<0.05$ and ${ }^{\# \#} \mathrm{p}<$ 0.01 vs. the control group; ${ }^{+} \mathrm{p}<0.01$ vs. the control group).

\section{Discussion}

Non-thermal plasma therapy has been investigated as a useful but challenging cancer treatment. Previous results indicated that the target of direct plasma treatment is limited to superficial lesions. More recently, PAM has been utilized as an indirect plasma therapy, which is more practical than the previous method, because tumor cells inside the peritoneal cavity are wholly and directly subjected to cytotoxic fluids $(18,22)$. On the other hand, despite decades of good results in the application of DOX as a chemotherapeutic agent, this anticancer agent generates cumulative, dose-dependent adverse reactions in patients. Thus, this study focused on elucidating the effects of PAM and DOX combinations on MCF-7 cell proliferation. Chemically active PAM can be generated by NTAP in a culture medium (22). Thus, we first prepared PAM with various irradiation periods by plasma jet. Then, we assessed whether DOX in the presence of PAM could change cell viability. MTT identifies cell mortality at the advanced stage of apoptosis, wherein tetrazolium salt metabolization is diminished. The MTT results demonstrated that PAM prepared with different irradiation periods affected MCF-7 cell viability in a timedependent manner. The 3- and 4-min PAM reduced MCF-7 cells viability to approximately $61 \%$ and $53 \%$ of control $(\mathrm{p}<$ 0.01 ), respectively. However, in the cases of 1 and 2-min PAM cell proliferation did not diminish significantly as compared with the control group ( $p>0.05)$. This observation is consistent with earlier studies, which illustrated that plasma irradiation reduced cell viability in a time-dependent manner $(4,28$ 32). Adachi et al., (22) also demonstrated that PAM suppressed MCF-7 cell viability. However, it should be emphasized that their study utilized DMEM containing pyruvate and they observed that pyruvate significantly attenuated plasma-induced reductions in cell viability. Thus, in this research, we utilized a medium without added pyruvate. DOX $(0.45$ 
$\mu \mathrm{M})$ combined with 3- or 4-min PAM killed MCF-7 cell efficiently ( $43 \%$ and $38 \%$ cell viability, respectively; $\mathrm{p}<0.01)$ than DOX (53\% cell viability) or 3- or 4-min PAM alone ( $61 \%$ and $54 \%$ cell viability, respectively). These data correlate with those of Ikeda et al. (33), who demonstrated that PAM plus cisplatin at low doses reduced viability of human endometrial carcinoma more effectively than cisplatin or PAM alone.

Cell health can be determined by morphological analysis. It has been widely accepted that DOX can change the cell morphology of cancer cells (34), which confirms our microscopic data. After cells treatment with 3- or 4-min PAM, cell morphology was slightly altered, and some cells became rounded. Several previous studies found the same association between PAM exposure time and cell morphology (30, 33, 35). Our data correlate with those of Iseki et al. (36) who proved that 3-min PAM can induce the morphological changes in the ovarian clear-cell carcinoma. Treatment with DOX plus 3-min PAM or 4-min PAM changed the cell morphology dramatically. Rasouli et al. showed that the morphology of SKOV-3 and A2780 CP cells significantly changed with the combination of PAM with carboplatin (37), which is completely consistent with our results.

As mentioned above, previous research confirmed that plasma irradiation can induce ROS production $(18,23,29)$. Generally, NAC has been utilized as an antioxidant and can scavenge hypochlorous acid $(\mathrm{HClO}), \mathrm{H}_{2} \mathrm{O}_{2}$, and hydroxyl radicals $(\cdot \mathrm{OH})$ directly but not superoxide radicals $\left(\mathrm{O}_{2}{ }^{-}\right)$. Our results showed that 4- and 5-mM of NAC reduced statistically significant DOX- and PAM-induced cytotoxicity (Figs. 3a and 3b). Interestingly, 5mM NAC pretreatment significantly reduced the cytotoxic effect of DOX plus 3- or 4-min PAM $(p<0.01)$. Several studies showed that plasma irradiation can induce ROS production, including $\mathrm{H}_{2} \mathrm{O}_{2}, \mathrm{NO}_{2}{ }^{-}$, and $\mathrm{NO}_{3}{ }^{-}$within cancer cells, and in the liquid phase (extracellular culture medium), and subsequently induce cell death in cell lines, including breast cancer cells
$(18,30,38)$. Conway et al., (39) demonstrated that NAC could not alleviate the cytotoxic effects of NTAP in relatively NTAP-resistant cells, but was protective against toxicity caused by NTAP in NTAP-sensitive cancer cells. This observation is consistent with those of Nakamura et al., (18) and Yan et al., (21) as well. According to the literature, cancer cells pretreated with NAC can only scavenge intracellular, but not extracellular, ROS (21). Increases in intracellular ROS can affect DNA structure, and protein and mitochondrial functions (40). Consequently, even though the exact components of PAM remain unclear, PAM-induced cellular ROS play a crucial role in anti-proliferative effects against cancer cells $(18,35)$. Thus, our results suggest that ROS is one of the effectors in PAM in combination with DOX to abolish MCF-7 cell viability, i.e., MCF-7 cells undergo ROS-dependent cell death in response to PAM plus DOX. It could be hypothesized from our results and previous investigations (29) that due to MCF-7 cells' high metabolic rate, the cells were under high oxidative stress; consequently, they could not tolerate an increase in ROS; thus, cell death occurred after $48 \mathrm{~h}$ of incubation with DOX plus PAM.

Malignant cell death may occur for various reasons. Thus, to differentiate between apoptosis and necrosis, flow cytometry analysis was performed. In the flow cytometry assessment, PI is a dead cell marker and annexin $\mathrm{V}$ identifies apoptotic cells by binding externalized phosphatidylserine residues (41, 42). Apoptosis serves as a critical mechanism to defend organs and tissues from numerous kinds of cell damage and stress. Since apoptosis does not initiate inflammatory responses as is the case with necrosis, apoptosis induction in malignant cells is more beneficial than that of necrosis in cancer therapy (30). The percentages of apoptotic cells were increased by DOX alone (32.08\% of cells were Annexin V-FITC ${ }^{+} \mathrm{PI}^{-}(\mathrm{p}<0.01)$ and $15.21 \%$ of cells were Annexin V-FITC ${ }^{+} / \mathrm{PI}^{+}$ $(p<0.05))$ and 4-min PAM $(29.09 \%$ of cells were Annexin V-FITC ${ }^{+} / \mathrm{PI}^{-}(\mathrm{p}<0.05)$ and $14.70 \%$ of cells were Annexin $\mathrm{V}-\mathrm{FITC}^{+} / \mathrm{PI}^{+}$ 
$(p<0.05))$. This observation correlates with those of Yoshikawa et al., (32) who demonstrated that the percentage of late apoptotic cells increased significantly in endometrial cancer cells after treatment with PAM. Contrary to our data, Xiang et al., (43) found no observable induction of apoptosis in MCF7 cells after treatment with 5-min PAM. Yan et al., (44) proposed that the anti-tumor capacity of PAM alters with the gap between the media and the source of plasma, i.e., decreasing the gap between the media and the plasma source produces PAM with stronger anti-tumor activity without increasing the treatment time. In the Xiang et al. study, the distance between the medium surface and the source of plasma was $13 \mathrm{~mm}$, however, in our study, this distance was $6 \mathrm{~mm}$. Furthermore, as mentioned above, the addition of pyruvate to the growth medium attenuated PAM-induced reductions in cell viability, and in this research, we utilized a medium without sodium pyruvate. Consequently, this might be another reason for the difference observed between our results and those of Xiang et al. When cells were treated with DOX plus 3-min PAM, the percentage of apoptotic cells increased considerably $(41.39 \%$ of cells were Annexin V-FITC ${ }^{+} / \mathrm{PI}^{-}$, early apoptotic cells $\left.(\mathrm{p}<0.01)\right)$ and $15.22 \%$ of cells were Annexin V$\mathrm{FITC}^{+} / \mathrm{PI}^{+}$(late apoptotic cells $(\mathrm{p}<0.05)$ ). Surprisingly, after treatment with DOX plus 4min PAM, $44.8 \%$ of the cells were Annexin VFITC $-\mathrm{PI}^{+}(\mathrm{p}<0.01)$, which recognizes primary necrotic cells. Thus, our results demonstrated that DOX plus PAM effectively generates cell death in MCF-7 cells; however, this process is irradiation time-dependent. The underlying process of cell death generated by PAM has

\section{References}

1. Siegel RL, Miller KD, Goding Sauer A, Fedewa SA, Butterly LF, Anderson JC, et al. Colorectal cancer statistics 2020. CA Cancer J Clin. 2020;70:145-164.

2. Nourolahzadeh Z, Houshmand SM, Mostafa Mohammad F, Ghorbian S. Correlation between Lsp1 (Rs3817198) and Casc (Rs4784227) been examined by many researchers and they assumed that the mechanism is related to increased apoptosis through intracellular ROS accumulation $(21,32,45)$. Other mechanisms proposed by researchers include senescence induction, and reduction in cell surface protein expression; for example, FAK and integrins (46). Earlier studies confirmed that normal cells are mostly unaffected by PAM treatment $(30,36)$, i.e., normal cells are less sensitive than cancer cells (35). Hence, based on our results, although the relative mechanisms need to be explored further, DOX combined with PAM represents an alternative strategy for cancer treatment while having minimal harmful side effects on normal adjacent cells or tissue.

Briefly, we demonstrated that 3-min PAM plus DOX, which induced apoptosis through intracellular ROS generation, had greater antiproliferative effects on MCF-7 cells than did DOX or PAM alone. We also showed that in 4-min PAM plus DOX the percentage of necrotic cells increased dramatically. Hence, DOX combined with 4-min PAM has cytotoxic effects with different mechanisms than 4-min PAM alone, in which the number of apoptotic cells increases. Although further investigations are crucial, PAM combined with DOX could be a promising cancer treatment strategy, contributing to a more positive therapeutic outlook.

\section{Acknowledgements}

The authors thank Mr. Mohammad Eftekhari for providing the designed plasma jet device.

The authors have no conflicts of interest to declare. This research obtained no certain funding or grant.

Polymorphisms and the Susceptibility to Breast Cancer. rbmb.net 2020;9:291-296.

3. Waks AG, Winer EP. Breast cancer treatment: a review. JAMA. 2019;321:288-300.

4. Jalili A, Irani $S$ and Mirfakhraie $R$. Combination of cold atmospheric plasma and iron nanoparticles in breast cancer: Gene expression 
and apoptosis study. Onco Targets Ther. 2016;9:5911-5917.

5. Lei J, Wang $\mathrm{H}$, Zhu D, Wan Y, Yin L. Combined effects of avasimibe immunotherapy, doxorubicin chemotherapy, and metal-organic frameworks nanoparticles on breast cancer. Journal of Cellular Physiology. 2020;235(5):4814-4823.

6. Hekmat A, Saboury AA, Divsalar A, Seyedarabi A. Structural effects of $\mathrm{TiO} 2$ nanoparticles and doxorubicin on DNA and their antiproliferative roles in T47D and MCF7 cells. Anticancer Agents Med Chem. 2013;13:932-51.

7. Lovitt CJ, Shelper TB, Avery VM. Doxorubicin resistance in breast cancer cells is mediated by extracellular matrix proteins. BMC Cancer. 2018;18(1):41.

8. Songbo M, Lang H, Xinyong C, Bin X, Ping Z, Liang S. Oxidative stress injury in doxorubicininduced cardiotoxicity. Toxicol Lett. 2019;307:41-48.

9. Azzariti A, Iacobazzi RM, Di Fonte R, Porcelli L, Gristina R, Favia P, et al. Plasma-activated medium triggers cell death and the presentation of immune activating danger signals in melanoma and pancreatic cancer cells. Scientific Reports volume. 2019;9:1-13.

10.Gay-Mimbrera J, García MC, Isla-Tejera B, Rodero-Serrano A, García-Nieto AV, Ruano J. Clinical and biological principles of cold atmospheric plasma application in skin cancer. Adv Ther. 2016;33:894-909.

11.Karki SB, Gupta TT, Yildirim-Ayan E, Eisenmann KM, Ayan H. Investigation of nonthermal plasma effects on lung cancer cells within 3D collagen matrices. J Phys D. 2017;50:315401. 12.Yan D, Sherman JH, Keidar M. Cold atmospheric plasma, a novel promising anticancer treatment modality. Oncotarget. 2017;8:15977-15995.

13.Kajiyama H, Utsumi F, Nakamura K, Tanaka $\mathrm{H}$, Toyokuni S, Hori M, et al. Future perspective of strategic non-thermal plasma therapy for cancer treatment. J Clin Biochem Nutr. 2017;60:33-38.

14.Stratmann B, Costea T-C, Nolte C, Hiller J, Schmidt J, Reindel J, et al. Effect of cold atmospheric plasma therapy vs standard therapy placebo on wound healing in patients with diabetic foot ulcers. JAMA Netw Open. 2020;3(7):e2010411.

15.Yamamoto K, Ohshima T, Kitano K, Ikawa S, Yamazaki H, Maeda N, Hosoya N. The efficacy of plasma-treated water as a root canal irrigant. Asian Pacific J Dent. 2017;17:23-30.

16.Raiser J, Zenker M. Argon plasma coagulation for open surgical and endoscopic applications: state of the art. Journal of Physics D: Applied Physics. 2006;39:3520.

17.Adil BH, Al-Shammari AM, Murbat HH. Breast cancer treatment using cold atmospheric plasma generated by the FE-DBD scheme. Clinical Plasma Medicine. 2020;19:100103.

18.Nakamura K, Peng Y, Utsumi F, Tanaka H, Mizuno M, Toyokuni S, et al. Novel intraperitoneal treatment with non-thermal plasma-activated medium inhibits metastatic potential of ovarian cancer cells. Scientific Reports. 2017;7:6085.

19.Ishikawa K, Hosoi Y, Tanaka H, Jiang L, Toyokuni S, Nakamura K, et al. Non-thermal plasma-activated lactate solution kills U251SP glioblastoma cells in an innate reductive manner with altered metabolism. Arch Biochem Biophys. 2020;688:108414.

20.Tavares-da-Silva E, Pereira E, Pires AS, Neves AR, Braz-Guilherme C, Marques IA, et al. Cold Atmospheric Plasma, a Novel Approach against Bladder Cancer, with Higher Sensitivity for the High-Grade Cell Line. Biology (Basel). 2021;10(1):41.

21.Yan D, Cui H, Zhu W, Nourmohammadi N, Milberg J, Zhang LG, et al. The specific vulnerabilities of cancer cells to the cold atmospheric plasma-stimulated solutions. Scientific reports. 2017;7:4479.

22.Adachi T, Tanaka H, Nonomura S, Hara H, Kondo S-I, Hori M. Plasma-activated medium induces A549 cell injury via a spiral apoptotic cascade involving the mitochondrial-nuclear network. Free Radic Biol Med. 2015;79:28-44.

23.Zhen X, Sun H-N, Liu R, Choi HS, Lee D-S. Non-thermal plasma-activated medium induces apoptosis of aspc1 cells through the rosdependent autophagy pathway. In Vivo. 2020;34(1):143-153.

24.Shahmirani Z, Irani S, Atyabi SM, Mirpour S, Shadpour S, Ghorannevis. Effect of cold 
atmospheric pressure plasma and gold nanoparticles on cell viability. Annu Res Rev Biol. 2014:3108-18.

25.Dashtaki A, Mahjoub S, Zabihi E, Pourbagher R. The Effects of Pre-Treatment and PostTreatment of Thymol against tert-Butyl Hydroperoxide (t-BHP) Cytotoxicity in MCF-7 Cell Line and Fibroblast Derived Foreskin. Rep Biochem Mol Biol. 2020;9(3):338-347.

26.Ibrahim NE-S, Morsy H, Abdelgwad M. The Comparative Effect of Nisin and Thioridazine as Potential Anticancer Agents on Hepatocellular Carcinoma. Rep Biochem Mol Biol. 2021;9(4):452-462.

27.Rahman SNSA, Wahab NA, Abd Malek SN. In vitro morphological assessment of apoptosis induced by antiproliferative constituents from the rhizomes of Curcuma zedoaria. Evid Based Complement Alternat Med. 2013;2013:257108. 28.Park S-B, Kim B, Bae H, Lee H, Lee S, Choi $\mathrm{EH}$, et al. Differential epigenetic effects of atmospheric cold plasma on MCF-7 and MDAMB-231 breast cancer cells. PLoS One. 2015;10(6):e0129931.

29.Laroussi M. Effects of PAM on select normal and cancerous epithelial cells. Plasma Research Express. 2019;1(2):025010.

30.Hattori N, Yamada S, Torii K, Takeda S, Nakamura K, Tanaka H, et al. Effectiveness of plasma treatment on pancreatic cancer cells. Int J Oncol. 2015;47(5):1655-1662.

31.Keidar M, Walk R, Shashurin A, Srinivasan P, Sandler A, Dasgupta S, et al. Cold plasma selectivity and the possibility of a paradigm shift in cancer therapy. Br J Cancer. 2011;105:1295301.

32. Yoshikawa N, Liu W, Nakamura K, Yoshida $\mathrm{K}$, Ikeda Y, Tanaka H, et al. Plasma-activated medium promotes autophagic cell death along with alteration of the mTOR pathway. Scientific Reports. 2020;10:1614.

33.Ikeda Ji, Tanaka H, Ishikawa K, Sakakita H, Ikehara Y, Hori M. Plasma-activated medium (PAM) kills human cancer-initiating cells. Pathol Int. 2018;68(1):23-30.

34.Srdic-Rajic T, Santibañez JF, Kanjer K, Tisma-Miletic N, Cavic M, Galun D, et al. Iscador $\mathrm{Qu}$ inhibits doxorubicin-induced senescence of MCF7 cells. Scientific Reports. 2017;7:1-12.
35.Utsumi F, Kajiyama H, Nakamura K, Tanaka H, Hori M, Kikkawa F. Selective cytotoxicity of indirect nonequilibrium atmospheric pressure plasma against ovarian clear-cell carcinoma. SpringerPlus. 2014;3:398.

36.Iseki S, Nakamura K, Hayashi M, Tanaka H, Kondo H, Kajiyama H, et al. Selective killing of ovarian cancer cells through induction of apoptosis by nonequilibrium atmospheric pressure plasma. Appl Phys Lett. 2012;100(11):113702.

37.Rasouli M, Mehdian H, Hajisharifi K, Amini E, Ostrikov K, Robert E. Plasma activated medium induces apoptosis in chemotherapyresistant ovarian cancer cells: high selectivity and synergy with carboplatin. Plasma Process Polym. 2021;18:2100074.

38.Ninomiya $K$, Ishijima $T$, Imamura $M$, Yamahara T, Enomoto H, Takahashi K, et al. Evaluation of extra-and intracellular $\mathrm{OH}$ radical generation, cancer cell injury, and apoptosis induced by a non-thermal atmospheric-pressure plasma jet. Journal of Physics D: Applied Physics. 2013;46:425401.

39.Conway GE, Casey A, Milosavljevic V, Liu $\mathrm{Y}$, Howe O, Cullen PJ, et al. Non-thermal atmospheric plasma induces ROS-independent cell death in U373MG glioma cells and augments the cytotoxicity of temozolomide. Br J Cancer. 2016;114:435-43.

40.Perillo B, Di Donato M, Pezone A, Di Zazzo E, Giovannelli P, Galasso G, et al. ROS in cancer therapy: the bright side of the moon. Exp. Mol Med. 2020;52(2):192-203.

41.Hekmat A, Hatamie S, Bakhshi E. Probing the effects of synthesized silver nanowire/reduced graphene oxide composites on the structure and esterase-like activity of human serum albumin and its impacts on human endometrial stem cells: A new platform in nanomedicine. Nanomedicine Journal. 2021;8:42-56.

42.Hekmat A, Saboury AA. Structural Effects of the Synthetic cobalt-Manganese-Zinc Ferrite Nanoparticles ( $\left.\mathrm{Co} 0.3 \mathrm{Mn}_{0.2} \mathrm{Zn}_{0.5} \mathrm{Fe}_{2} \mathrm{O}_{4} \mathrm{NPs}\right)$ on DNA and its Antiproliferative Effect on T47D cells. BioNanoSci. 9, 821-832 (2019).

43.Xiang L, Xu X, Zhang S, Cai D, Dai X. Cold atmospheric plasma conveys selectivity on triple 
negative breast cancer cells both in vitro and in vivo. Free Radic Biol Med. 2018;124:205-13.

44.Yan D, Talbot A, Nourmohammadi N, Cheng $\mathrm{X}$, Canady J, Sherman J, et al. Principles of using cold atmospheric plasma stimulated media for cancer treatment. Scientific Reports. 2015;5:18339.

45.Saadati F, Mahdikia H, Abbaszadeh H-A, Abdollahifar M-A, Khoramgah MS, Shokri B.
Comparison of direct and indirect cold atmospheric-pressure plasma methods in the B 16 F 10 melanoma cancer cells treatment. Sci Rep. 2018;8(1):7689.

46.Guerrero-Preston R, Ogawa T, Uemura M, Shumulinsky G, Valle BL, Pirini F, et al. Cold atmospheric plasma treatment selectively targets head and neck squamous cell carcinoma cells. Int J Mol Med. 2014;34:941-6. 